\title{
Comparing the ocean color measurements between MOS and SeaWiFS: A vicarious intercalibration approach for MOS
}

\author{
MENGHUA WANG \\ University of Maryland Baltimore County \\ Code 970.2, NASA Goddard Space Flight Center \\ Greenbelt, Maryland 20771 \\ BRYAN A. FRANZ \\ SAIC General Sciences Corporation \\ Code 970.2, NASA Goddard Space Flight Center \\ Greenbelt, Maryland 20771
}

IEEE Trans. Geosci. Remote Sensing

\begin{abstract}
Acknowledgments
We thank C. McClain at NASA Goddard Space Flight Center for helpful discussions. This research was supported by funding provided by the National Aeronautics and Space Administration under the Sensor Intercomparison and Merger for Biological and Interdisciplinary Oceanic Studies (SIMBIOS) project.
\end{abstract}




\begin{abstract}
One of the primary goals of the NASA Sensor Intercomparison and Merger for Biological and Interdisciplinary Oceanic Studies (SIMBIOS) project is to develop methods for meaningful comparison and possible merging of data products from multiple ocean color missions. The Modular Optoelectronic Scanner (MOS) is a German instrument that was launched in the spring of 1996 on the Indian IRS-P3 satellite. With the successful launch of NASA's Sea-viewing Wide Field-of-view Sensor (SeaWiFS) in the summer of 1997, there are now two ocean color missions in concurrent operation and there is interest within the scientific community to compare data from these two sensors. In this paper, we describe our efforts to retrieve ocean optical properties from both SeaWiFS and MOS using consistent methods. We first briefly review the atmospheric correction, which removes more than $90 \%$ of the observed radiances in the visible, and then describe how the atmospheric correction algorithm used for the SeaWiFS data can be modified for application to other ocean color sensors. Next, since the retrieved water-leaving radiances in the visible between MOS and SeaWiFS are significantly different, we developed a vicarious intercalibration method to recalibrate the MOS spectral bands based on the optical properties of the ocean and atmosphere derived from the coincident SeaWiFS measurements. We present and discuss the MOS retrieved ocean optical properties before and after the vicarious calibration, and demonstrate the efficacy of this approach. We show that it is possible and efficient to vicariously intercalibrate sensors between one and another.
\end{abstract}




\section{Introduction}

The German Modular Optoelectronic Scanner (MOS) [1] is an imaging pushbroom CCD spectrometer that was launched in the spring of 1996 on the Indian IRS-P3 satellite. The IRS-P3 satellite is in a sun-synchronous polar orbit with a mean altitude of approximately $817 \mathrm{~km}$ and a local 10:30 AM descending node crossing time, and completes one orbit about every 101 minutes. MOS has 13 spectral channels ranging from 400-1010 nm with bandwidth of about $10 \mathrm{~nm}$. The MOS image has a ground resolution of $\sim 0.5 \mathrm{~km}$ in nadir viewing with scan swath of $\sim 200 \mathrm{~km}$. MOS is a technology demonstrator instrument with limited geographic coverage capabilities. Its scientific applications are mainly in ocean color and atmospheric aerosol studies. With the successful launch of NASA's Sea-viewing Wide Field-of-view Sensor (SeaWiFS) [2] on August 1 of 1997, there are now two ocean color missions in concurrent operation. Therefore, we have an unprecedented opportunity to compare ocean color data from two sensors in simultaneous operation on two different satellite platforms. SeaWiFS has 8 spectral bands covering from $412-865 \mathrm{~nm}$ with bandwidth of 20-40 nm. SeaWiFS is in a sun-synchronous polar orbit of $705 \mathrm{~km}$ altitude with a local noon crossing time and completes one orbit every 99 minutes. The SeaWiFS image has a ground resolution $\sim 1 \mathrm{~km}$ with a scan swath of $\sim 2800 \mathrm{~km}$, enabling it to provide daily global coverage. As shown in Table 1, MOS has a slightly different spectral band characterization in comparison with SeaWiFS. It should be noted that only the MOS bands which are close to the SeaWiFS spectral channels are listed in Table 1. Also, the MOS band number is named corresponding to the SeaWiFS's as shown in Table 1 and used in this paper. The object of this paper is to develop a vicarious calibration approach in which the MOS spectral bands can be recalibrated from the SeaWiFS measurements, thereby allowing remotely retrieved 
ocean color results from the two sensors to be meaningfully compared. The vicarious calibration method is also applicable for re-calibrating the satellite sensor with in situ ocean and atmospheric optical property measurements.

\section{Applying the SeaWiFS Atmospheric Correction Algorithm to MOS}

In this section we first briefly review the SeaWiFS atmospheric correction algorithm and its implementation into the SeaWiFS data processing system. Next, we present the modifications required to implement this algorithm for alternate ocean color sensors, e.g., the MOS. We then test the accuracy of the correction algorithm at the MOS spectral bands for various cases using the current SeaWiFS aerosol lookup tables. Finally, we compare retrieved results from MOS and SeaWiFS measurements using a consistent atmospheric correction algorithm for scenes acquired at various locations and different times.

\subsection{The SeaWiFS atmospheric correction algorithm}

We begin with definition of the reflectance $\rho=\pi L / \mu_{0} F_{0}$, where $L$ is the radiance in a given solar and viewing geometry, $F_{0}$ is the extraterrestrial solar irradiance, and $\mu_{0}$ is the cosine of the solar zenith angle. The total reflectance measured at the top of the ocean-atmosphere system can be written as:

$$
\rho_{t}(\lambda)=\rho_{r}(\lambda)+\rho_{a}(\lambda)+\rho_{r a}(\lambda)+t(\lambda) \rho_{w c}(\lambda)+t(\lambda) \rho_{w}(\lambda),
$$

where $\rho_{r}(\lambda)$ is the reflectance resulting from multiple scattering by air molecules, $\rho_{a}(\lambda)$ is the reflectance resulting from multiple scattering by aerosols, $\rho_{r a}(\lambda)$ is the multiple interaction term between molecules and aerosols [3], $\rho_{w c}(\lambda)$ is the reflectance at the sea surface that arises from sunlight and skylight reflecting from whitecaps on the surface [4], and $\rho_{w}(\lambda)$ is the water-leaving reflectance, which is the desired quantity in ocean color remote sensing. The $t(\lambda)$ is the atmospheric diffuse transmittance $[5,6]$ that accounts for the effects of propagating water- 
leaving and whitecap reflectances from the sea surface to the top of the atmosphere (TOA). In the above equation, the surface sun glitter term has been ignored. Observations which have significant sun glitter contamination can not be accurately corrected, and must be removed. To relate the derived water-leaving reflectance to the ocean inherent optical properties (IOP), the atmospheric effects on the water-leaving reflectance $\rho_{w}(\lambda)$ must be removed. The normalized waterleaving reflectance, $\left[\rho_{w}(\lambda)\right]_{N}$, can be defined from Gordon and Clark [7],

$$
\left[\rho_{w}(\lambda)\right]_{N}=\rho_{w}(\lambda) / t\left(\lambda, \theta_{0}\right),
$$

where $t\left(\lambda, \theta_{0}\right)$ is the atmospheric diffuse transmittance in the solar direction with the solar zenith angle of $\theta_{0}$. The value of two-band ratio of $\left[\rho_{w}(\lambda)\right]_{N}$ in the visible can then be used to infer the ocean near-surface optical properties [8-10]. Note that in comparing the retrieval results from two different sensors which usually have slightly different spectral band characterizations, the normalized water-leaving reflectances provide a more meaningful comparison than the radiance values. The radiance value is a function of the solar irradiance, which will vary with a sensor band's spectral response.

Since more than $90 \%$ of the signal in visible measured at satellite altitude is contributed by the atmosphere (the first three terms in Eq. (1)), accurately removing the atmospheric effects is crucial to the success of any ocean color remote sensing experiment. The Gordon and Wang atmospheric correction algorithm [11] uses the SeaWiFS two near-infrared (NIR) bands centered at 765 and $865 \mathrm{~nm}$ to estimate the atmospheric effects and extrapolate these into the visible. Unlike Rayleigh scattering which can be computed accurately, the aerosol scattering is highly variable, and the effects of the $\rho_{a}(\lambda)+\rho_{r a}(\lambda)$ in Eq. (1) on the imagery cannot be predicted a priori. The water-leaving reflectance $\rho_{w}(\lambda)$ at the two NIR bands, however, is usually negligible because of strong water absorption. There- 
fore, the radiances measured at these two NIR bands are essentially the contributions from the atmosphere. For the SeaWiFS two NIR channels, Eq. (1) can be written as

$$
\rho_{t}(\lambda)-\rho_{r}(\lambda)-t(\lambda) \rho_{w c}(\lambda)=\rho_{a}(\lambda)+\rho_{r a}(\lambda)
$$

Therefore, the effects of aerosols and Rayleigh-aerosol interactions, $\rho_{a}(\lambda)+\rho_{r a}(\lambda)$, in the imagery can be estimated at the two NIR bands from the sensor-measured radiances, the computed Rayleigh scattering reflectances, and the estimated whitecap contributions [4]. This quantity is then extrapolated and removed in the visible. The extrapolation was achieved through a process of aerosol model selection from evaluation of the atmospheric correction parameters, $\varepsilon(i, j)$, defined as [11-13]

$$
\varepsilon(i, j)=\rho_{a s}(i) / \rho_{a s}(j),
$$

where $\rho_{a s}(i)$ is the single scattering aerosol reflectance at a wavelength $\lambda_{i}$. The $\lambda_{j}$ is usually at the longer NIR band, i.e., $865 \mathrm{~nm}$. The value of $\varepsilon(i, j)$ characterizes the spectral variation of aerosol optical properties which include the aerosol optical thickness, single scattering albedo, and the aerosol scattering phase function. It therefore can be used to infer the aerosol models.

The implementation of the Gordon and Wang algorithm into the SeaWiFS data processing system was achieved through the use of lookup tables based on a large number $(25,000)$ of radiative transfer simulations that use the 12 aerosol models developed by Shettle and Fenn [14]. The main lookup tables contain information of the $\rho_{a}(\lambda)+\rho_{r a}(\lambda)$ values for various aerosol optical and microphysical properties (12 aerosol models with various aerosol optical thicknesses) and solar and viewing geometries at the 8 SeaWiFS spectral bands. Generating the aerosol lookup tables involves a large number of radiative transfer simulations and requires substantial computer resources. 


\subsection{Atmospheric corrections for MOS}

Application of the SeaWiFS atmospheric correction algorithm to MOS would be difficult if it was necessary to regenerate the aerosol lookup tables for the MOS spectral bands. In a recent paper, Wang [15] discussed the effects of spectral band variation on the SeaWiFS atmospheric correction algorithm and outlined simple procedures necessary to implement the algorithm for other ocean color sensors. In summary, to apply the SeaWiFS atmospheric correction algorithm to MOS we need to, according to the MOS spectral response functions: (i) re-compute the extraterrestrial solar irradiances and ozone absorption coefficients, (ii) re-generate the Rayleigh scattering radiance tables at the sensor's spectral bands, and (iii) modify the atmospheric diffuse transmittance computations. Of these steps, procedure (ii) is the most important.

We have implemented the SeaWiFS atmospheric correction algorithm for MOS and tested algorithm performance for the MOS spectral bands with simulations. Following Gordon and Wang [11], we have applied the correction algorithm to a series of simulations carried out using the Maritime aerosol model with the relative humidity $(\mathrm{RH})$ of $80 \%$ (M80 refers to the Maritime aerosol with $\mathrm{RH}=80 \%)$, i.e., $\rho_{t}(\lambda)$ was simulated with M80 aerosol model at the MOS spectral bands assuming that $\rho_{w}(\lambda)=0$. The SeaWiFS aerosol lookup tables, $\rho_{a}(\lambda)+\rho_{r a}(\lambda)$, were used for all computations. The error in the retrieved water-leaving reflectance, $\Delta \rho(\lambda)=t(\lambda) \Delta \rho_{w}(\lambda)$, was computed. Fig. 1 provides results of algorithm performance for the MOS spectral bands at different solar and viewing geometries for the M80 aerosol model with aerosol optical thickness of 0.2 at $865 \mathrm{~nm}$. For reference, a $5 \%$ error in water-leaving radiance at $443 \mathrm{~nm}$, which is the SeaWiFS goal, corresponds to $\Delta \rho \sim 0.001-0.002$. Fig. 1 is for the cases of the sensor viewing at the center $\left(\theta=1.02^{\circ}\right)$ with the solar zenith angles varying from $10^{\circ}-80^{\circ}$ at step of $10^{\circ}$. For comparison, the SeaWiFS results are plotted in the same figure. Fig. 1 
shows that the implemented SeaWiFS atmospheric correction algorithm works as well for the MOS spectral bands as for SeaWiFS. We therefore conclude that, with appropriate computation of the Rayleigh scattering contribution at the MOS spectral bands, the current SeaWiFS atmospheric correction, with the lookup tables of $\rho_{a}(\lambda)+\rho_{r a}(\lambda)$, can be applied to MOS.

\subsection{A simple MOS destriping procedure}

The MOS radiance image has along-track stripes due to variations in the relative response of the individual detectors on the MOS CCD array (total of 384 CCD detectors). Therefore, we have developed a simple destriping algorithm and applied it to the MOS radiance imageries. The MOS destriping procedure can be outlined as follows. First, for each scan (along the detector array) and a given spectral band, fit the radiance to a least-square cubic polynomial along the scan (the detector array) and compute relative gain at each detector (pixel), i.e.,

$$
g(i, j)=\sum_{n=0}^{3} a_{n} i^{n} / L(i, j), \text { for } i=1-384,
$$

where $L(i, j)$ is the MOS measured-radiance for the detector number $i$ and the scan number $j$ for a given scene. Next, for each detector (pixel) select the median gain over all scans in the scene to derive the nominal gain factor for that detector, i.e., $\bar{g}(i)=\operatorname{Median}[g(i, j)]$. Finally, the MOS radiance image can be re-computed with the destriping correction $L^{\prime}(i, j)=\vec{g}(i) L(i, j)$, where $L^{\prime}$ and $L$ are the destriped and original radiance, respectively. This simple procedure usually works quite well. Figs. 2(a) and 2(b) provide an example of results from the destriping algorithm for a MOS image acquired on February 28, 1998 in the Mediterranean Sea. Fig. 2(a) is the MOS original radiance image (443 nm) in which the alongtrack stripes are clearly evident, while Fig. 2(b) shows the same image after the MOS destriping algorithm has been applied. The destriping algorithm works quite well in this case, removing most of the striping effects with no obvious loss 
of image structure, i.e., the physical properties of the image are preserved. In general, the efficacy of the algorithm depends mainly on how well the radiances along the detector array can be fitted with the cubic polynomials. To apply the implemented SeaWiFS atmospheric correction algorithm to MOS, however, the destriping procedure is usually not necessary. Without destriping, the results from atmospheric correction will be somewhat degraded, as the radiance striping adds noise to the process. The MOS destriping procedure usually improves the retrieved ocean optical properties significantly.

\subsection{The results from MOS compared with SeaWiFS}

We applied the atmospheric correction to both MOS and SeaWiFS for colocated images and compared the retrieved ocean and atmospheric optical properties. The MOS radiance image was first destriped to remove the detector variations within pixels. The implemented SeaWiFS atmospheric correction algorithm was then applied to the MOS imagery. Two MOS-SeaWiFS co-located images acquired on January 29, 1998 in the Atlantic ocean and February 28, 1998 in the Mediterranean Sea were first tested. These two scenes, acquired one month apart, differ significantly in their ocean and atmospheric optical properties. Fig. 2 shows the MOS radiance image ( $443 \mathrm{~nm}$ ) which was acquired on February 28,1998 at a location of about longitude $3^{\circ}$ and latitude $38^{\circ}$ in the Mediterranean Sea. Fig. 3 shows both the MOS destriped and SeaWiFS radiance images (443 nm) which were acquired on January 29, 1998 at a location of about longitude $-32^{\circ}$ and latitude $27^{\circ}$ in the Atlantic ocean. In comparing the MOS retrieved ocean and atmospheric optical results with that of SeaWiFS, we found that (i) the MOS retrieved aerosol optical thickness at the NIR band was usually a factor of 2-3 times higher than that of SeaWiFS; (ii) the MOS retrieved $\varepsilon(7,8)$ which characterizes the spectral variation of aerosol optical properties is unreasonably low; 
and (iii) the MOS retrieved normalized water-leaving reflectances $\left[\rho_{w}(\lambda)\right]_{N}$ in the visible are significantly different from those of SeaWiFS. Tables 2(a) and 2(b) provide examples of comparison results for typical co-located MOS $10 \times 10(5 \times 5$ for SeaWiFS) pixel regions retrieved from these two cases. The parameters in the tables were obtained by averaging over the retrieved single pixel values in the co-located area (MOS $10 \times 10$ and SeaWiFS 5×5). The selected parameters in Table 2 are the normalized water-leaving reflectance $\left[\rho_{w}(\lambda)\right]_{N}$ for bands $1-4$, the ratio of aerosol single scattering reflectance between band 7 and $8 \varepsilon(7,8)$, and the retrieved aerosol optical thickness at band $8 \tau_{\mathrm{a}}(8)$. The differences in $\varepsilon(7,8)$ and $\tau_{\mathrm{a}}(8)$ between MOS and SeaWiFS are not shown in Table 2. Direct comparison of these atmospheric quantities is not relevant, since they depend on the solar and viewing geometry of the observation, and that geometry is different between the two sensors. Furthermore, since there is about 90 minutes difference between colocated MOS and SeaWiFS observations, the atmospheric conditions may have changed. However, the $\varepsilon(7,8)$ value should be $\sim 1$ for typical marine aerosols, and it should certainly be $>0.5$. Obviously, the results from SeaWiFS are more reasonable. The retrieved $\left[\rho_{w}(\lambda)\right]_{N}$ from SeaWiFS indicates typical two different ocean optical properties from these two scenes. The scene of the Atlantic ocean represents a typical clear ocean region with chlorophyll concentration $\sim 0.1$ $\left(\mathrm{mg} / \mathrm{m}^{3}\right)$, whereas the scene from the Mediterranean Sea is a kind of turbid ocean water with chlorophyll concentration $\sim 0.8-1.0\left(\mathrm{mg} / \mathrm{m}^{3}\right)$. Since we are applying an identical atmospheric correction process to the two sets of measurements, the large discrepancy in the retrieved $\left[\rho_{w}\right]_{N}$ values between the two sensors can probably be interpreted as a difference in sensor calibrations. It is therefore necessary to re-calibrate one sensor to the other, to allow for meaningful comparisons of the retrieved ocean optical properties. 


\section{A Vicarious Intercalibration for MOS}

As discussed in section 2, the sensor-measured radiance at the TOA is described by Eq. (1). Essentially, the first four terms in Eq. (1) are contributions from the atmosphere and ocean surface, and the last term is contribution from the ocean. There are mainly two unknowns in Eq. (1) for ocean color remote sensing: the aerosol optical properties and the water-leaving reflectance in the visible. Therefore, if one has knowledge of the atmospheric aerosol and ocean optical properties, one can essentially predict the sensor-measured radiance at the TOA for the MOS wavelengths [16]. These computed radiances can then be used to vicariously re-calibrate the MOS bands. Due to differences in the orbits of MOS and SeaWiFS, measurements of the same geographic location will be about one and one half hours apart. Since the atmospheric conditions are likely to change over that period, we can not expect that the atmospheric properties measured by SeaWiFS are valid for the MOS observations. We therefore assume that the gain of the MOS $868 \mathrm{~nm}$ band is unchanged, thereby using the aerosol concentration from the MOS measurements, and only accept that the aerosol model determined by SeaWiFS is still valid. Next, by using the SeaWiFS retrieved aerosol models we can predict the atmospheric effects in the MOS imagery, i.e., the first three terms in Eq. (1). The whitecap radiance contribution can be estimated in the same way as SeaWiFS [4]. Finally, using the SeaWiFS retrieved normalize water-leaving reflectance, $\left[\rho_{w}(\lambda)\right]_{N}$, the water-leaving radiance at the TOA in the MOS imagery can be computed according to Eq. (1), and the gain coefficients for the MOS bands can be derived. To reduce the variation of the derived gain coefficients with various scans, multiple scans within the MOS scene can be used to obtain coefficient data and derive a best fit for the MOS 384 detectors. 
In summary, the intercalibration procedure can be outlined as follows:

1. find a MOS and SeaWiFS co-located scene in which both the SeaWiFS TOA radiances and the retrieved normalized water-leaving reflectances are relatively uniform;

2. retrieve the aerosol models and $\left[\rho_{w}(\lambda)\right]_{N}$ values from the SeaWiFS measurements for the corresponding MOS pixels;

3. theoretically predict the MOS measured-radiances at the TOA from the SeaWiFS data;

4. obtain gain coefficients for the MOS bands 1-7 for all MOS 384 CCD detectors; and

5. use the derived gain coefficients from multiple scans within the imagery and fit the gain coefficients data with the least-square cubic polynomials.

We have applied the recalibration procedure outlined above to the two MOS scenes acquired on January 29 and February 28, 1998. The MOS scene has a 384 detector-scan with image size of $384 \times 384$. We derived the MOS gain coefficients for the MOS 384 detectors at every 5 th scan, thereby providing a total of $\sim 75$ gain coefficients for every detector of the MOS scene. Figs. $4(\mathrm{a})-4(\mathrm{~g})$ provide the derived gain coefficients for the MOS bands 1-7 from scenes acquired on January 29 and February 28, 1998, while Fig. 4(h) shows the MOS derived aerosol optical thicknesses at band 8 . To clearly see the differences of the derived gain coefficients from the two different MOS cases, we only plotted 50 representative data for each case in the figures (there are total of $-2.8 \times 10^{4}$ data for each case). Apparently, the derived gain coefficients for the MOS bands 1-6 have very similar values in the two different cases, indicating that they are nearly independent of temporal and spatial variations. The derived gain coefficients for band 7, however, are different in the two cases. It appears that the MOS band 7 performance is related to the atmospheric optical conditions (see Fig. $4(\mathrm{~h})$ ) and its gain ad- 
justment is in opposite to other bands (gain coefficient $>1$ ). For the MOS bands $1-6$, we fitted the derived re-calibration gain coefficients from both cases to a least-square cubic polynomial (dotted lines in Figs. 4(a)-4(f)), while individual fits were derived for the MOS band 7 for two different cases. Clearly, the MOS band re-calibration adjustments are significant and they strongly depend on the MOS detector number. For example, the MOS band 1 has a re-calibration gain coefficient of $\sim 0.90$ for detector 1 , while it is $\sim 0.98$ for detector 384 . The MOS band 3 has the most changes (except band 7) with gain coefficient of $\sim 0.81$ for detector 1 and $\sim 0.89$ for detector 384 . Table 3 provides the derived MOS recalibration gain coefficients fitted with the least-square cubic polynomial as

$$
G(\lambda, i)=\sum_{n=0}^{3} c_{n}(\lambda) i^{n}, \text { for } i=1-384,
$$

where $i$ is the MOS detector number and $c_{n}(\lambda)$ is the fitting coefficient of the cubic polynomial for order number $n$. The gain fitting coefficients for bands 1-6 in Table 3 were derived with the least-square cubic fitting from the two MOS scenes, while the two set of band 7 gain coefficients were derived, respectively, from the MOS scene acquired on January 29, 1998 in the Atlantic ocean and on February 28, 1998 in the Mediterranean Sea. Therefore, for a given MOS band, only 4 re-calibration coefficients are needed for the 384 detectors.

\section{Results and Discussions}

We applied the derived MOS gain coefficients as in Table 3 to the MOS measured-radiance at the TOA, and retrieved ocean and atmospheric optical properties for comparison with results from the SeaWiFS measurements. Since the derived MOS band 7 re-calibration gain coefficients depend on the atmospheric optical properties, we have modified the atmospheric correction algorithm such that the correction can also be operated using the MOS bands 6 and 8 . The 
water-leaving reflectance at the MOS band 6, however, is usually not negligible. We have assumed a constant value of the MOS band $6\left[\rho_{w}(6)\right]_{N}$ of $0.0959 \%$ which corresponds to a normalized water-leaving radiance of $0.045\left(\mathrm{~mW} / \mathrm{cm}^{2} \mu \mathrm{m} \mathrm{sr}\right)$. This value was used in all results reported in this paper when using bands 6 and 8 in the MOS atmospheric corrections.

Figs. 5 and 6 provide the histogram (\%) for the retrieved ocean parameters from MOS and SeaWiFS for the case of January 29 and February 28, 1998 for various situations. Figs. 5(a)-5(d) are, respectively, the retrieved normalize water-leaving reflectances (\%) for bands 1-4 for the MOS data acquired on January 29, 1998 in the Atlantic ocean, while Figs. 6(a)-6(d) are for the case of February 28, 1998 in the Mediterranean Sea. For comparison, the retrieved parameters without the MOS re-calibrations are plotted in the same figures. There are four cases in each figure: (i) results from the SeaWiFS measurements with the bands 7 and 8 used in the atmospheric corrections, (ii) results from the MOS re-calibrated radiances with the bands 7 and 8 used in the corrections, (iii) same as in (ii) except that the MOS bands 6 and 8 were used in the corrections, and (iv) results from the MOS original radiance data with the bands 7 and 8 used in the corrections. Table 4 shows the total number of retrievals (pixels) contributing to the histogram plots in Figs. 5 and 6 for cases of (i) to (iii). The MOS has $\sim 6$ times more retrievals from each co-located scene than SeaWiFS because of its high spatial resolution. Note that using the MOS bands 6 and 8 in the atmospheric corrections yields slightly more retrievals than when using bands 7 and 8 . Figs. 5 and 6 show that the vicarious calibration improves the agreement significantly. Tables $5(a)$ and 5 (b) give quantitative comparisons of the retrieved parameters between the MOS (after re-calibrations) and SeaWiFS for the peak values in the histograms as shown in Figs. 5 and 6. For comparison of the retrieved atmospheric optical parameters, the peak values $\varepsilon(7,8)$ in the histograms are also listed in the 
tables. Obviously, the differences in the retrieved normalized water-leaving reflectance between MOS and SeaWiFS are reduced tremendously. Also, the MOS retrieved $\varepsilon(7,8)$ values are now reasonable and very similar to the values from SeaWiFS. Note that for cases in which the MOS bands 7 and 8 were used for the atmospheric corrections, two different calibration gain coefficients were applied for the MOS $750 \mathrm{~nm}$ band for cases of January 29 and February 28, 1998. However, when the MOS bands 6 and 8 were used in the corrections, the MOS band 7 reflectance data were simply not used, thereby allowing a consistent set of recalibration gain coefficients for the MOS bands 1-6 and 8 to be applied for both cases. Both Figs. 5 and 6 and Table 5 show that, though the results of using MOS bands 7 and 8 in the atmospheric corrections yield slightly better agreement with SeaWiFS, good results can be obtained by using the MOS bands 6 and 8 with an assumed constant water-leaving reflectance value at band 6. Since the MOS band 7 gain coefficient depends on the atmospheric conditions, which are highly variable in time and space, using the bands 6 and 8 for the MOS atmospheric correction is more practical.

To further test the efficacy of the vicarious re-calibration approach, we have applied the MOS re-calibration gain coefficients, which were derived from January 29 and February 28, 1998 data, to a MOS image acquired on September 24, 1997 at a location of about longitude $13^{\circ}$ and latitude $45^{\circ}$ in the Adriatic Sea, and compared the results to those obtained from a co-located SeaWiFS image. For this test, the destriping algorithm was not applied and the MOS bands 6 and 8 were used in the atmospheric corrections. Figs. 7(a)-7(d) provide the histogram (\%) of the retrieved water-leaving reflectances (\%) for bands 1-4 from the MOS measurements for comparison with the SeaWiFS. The results from the MOS original calibrations are plotted in the same figures. The total retrievals contributed in each plot in Fig. 7 are $6.76 \times 10^{3}$ and $3.46 \times 10^{4}$ for the SeaWiFS and MOS 
(bands $6 \& 8$ ) case, respectively. It is truly remarkable that, with a time difference of 4-5 months from the recalibration scenes and a different geographic location, the MOS derived water-leaving reflectances are still in a good agreement with SeaWiFS. It certainly improves the MOS retrieval results significantly from the original calibration.

Since a two-band ratio of the retrieved normalized water-leaving reflectance $\left[\rho_{w}(\lambda)\right]_{N}$ in the visible is used to infer the ocean near-surface optical properties, e.g., the chlorophyll concentration can be related to either a ratio of band 2 to 5 $\left(\left[\rho_{w}(2)\right]_{N} /\left[\rho_{w}(5)\right]_{N}\right)$ or band 3 to $5\left(\left[\rho_{w}(3)\right]_{N} /\left[\rho_{w}(5)\right]_{N}\right)[9,17]$, we have compared the MOS retrieved ratio values (after re-calibrations) with SeaWiFS for the January 29 , February 28, 1998, and September 24, 1997 cases. Figs. 8(a)-8(f) show histograms $(\%)$ in the retrieved ratios of the normalized water-leaving reflectance between bands 2 and 5 and bands 3 and 5 for various scenes. Figs. 8(a), 8(c), and 8(e) are, respectively, the MOS and SeaWiFS retrieved normalized water-leaving reflectance ratio between bands 2 and 5 for case of January 29, February 28, 1998, and September 24, 1997, while Figs. $8(\mathrm{~b}), 8(\mathrm{~d})$, and $8(\mathrm{f})$ are results of reflectance ratio between bands 3 and 5 . In generating these figures, the MOS bands 6 and 8 were used in the atmospheric corrections. Fig. 8 shows that, after re-calibration, the MOS derived ratio of retrieved normalized water-leaving reflectance agrees well with that of SeaWiFS. Therefore, MOS should be able to obtain similar chlorophyll concentration results as SeaWiFS.

Finally, to compare results of the spatial distributions in the retrieved normalized water-leaving reflectance between MOS (after re-calibrations) and SeaWiFS, Figs. 9 (a)-9(c) provide color images of the MOS retrieved normalized water-leaving reflectance (\%) at $443 \mathrm{~nm}$ compared with the SeaWiFS measurements for a scene acquired on January 29, 1998 in the Atlantic ocean, February 28, 1998 in the Mediterranean Sea, and September 24, 1997 in the Adriatic Sea. In 
generating these images, the MOS bands 6 and 8 were used in the atmospheric corrections for retrieval of the MOS normalized water-leaving reflectances. Fig. 9 shows that, after re-calibrations, MOS has a very similar results as from SeaWiFS.

\section{Conclusions}

We demonstrate that it is possible and efficient to vicariously intercalibrate two different ocean color sensors. In this study, the SeaWiFS retrieved normalized water-leaving reflectance and aerosol models were used as "truth" to recalibrate the MOS spectral bands. After MOS band re-calibrations, the differences of retrieved normalized water-leaving reflectances between MOS and SeaWiFS are much reduced. The MOS retrieved $\varepsilon(7,8)$ values are much more reasonable and very similar to the SeaWiFS measurements after re-calibration. Since the MOS band 7 re-calibration coefficients depend on the atmospheric conditions, we modified the atmospheric correction algorithm such that the MOS bands 6 and 8 can also be used for the corrections. Therefore, a consistent gain coefficients for the MOS bands 1-6 and 8 can be used for various MOS scenes obtained at different times and locations. We show the efficacy of the vicarious calibration approach by applying the method to a MOS scene acquired 4-5 months prior to the data used in deriving the gain coefficients. The MOS results are in reasonable agreement with SeaWiFS. With this vicarious calibration approach, the retrieved results from different sensors can now be meaningfully compared and possibly merged. With the same procedure one can also recalibrate satellite sensors using in situ ocean and atmospheric optical property measurements. The proposed vicarious calibration scheme is applicable to other ocean color sensors, e.g., Japan's Ocean Color and Temperature Sensor (OCTS) and the French Polarization and Directionality of the Earth's Reflectances (POLDER). 


\section{REFERENCES}

[1] G. Zimmermann and A. Neumann, "The Spaceborne Imaging Spectrometer MOS for Ocean Remote Sensing," presented at Proceedings of the 1st International Workshop on MOS-IRS and Ocean Color, DLR, Institute of Space Sensor Technology, Berlin, 1997.

[2] S. B. Hooker, W. E. Esaias, G. C. Feldman, W. W. Gregg, and C. R. McClain, "An Overview of SeaWiFS and Ocean Color," NASA Goddard Space Flight Center, Greenbelt, MD, Vol. 1 of SeaWiFS Technical Report Series NASA tech. memo. 104566, 1992.

[3] P. Y. Deschamps, M. Herman, and D. Tanre, "Modeling of the atmospheric effects and its application to the remote sensing of ocean color," Appl. Opt., vol. 22, pp. 3751-3758, 1983.

[4] H. R. Gordon and M. Wang, "Influence of oceanic whitecaps on atmospheric correction of ocean-color sensor," Appl. Opt., vol. 33, pp. 7754-7763, 1994.

[5] H. Yang and H. R. Gordon, "Remote sensing of ocean color: assessment of water-leaving radiance bidirectional effects on atmospheric diffuse transmittance," Appl. Opt., vol. 36, pp. 7887-7897, 1997.

[6] M. Wang, "Atmospheric correction of ocean color sensors: Computing atmospheric diffuse transmittance," Submitted to Applied Optics, 1998.

[7] H. R. Gordon and D. K. Clark, "Clear water radiances for atmospheric correction of coastal zone color scanner imagery," Appl. Opt., vol. 20, pp. 4175-4180, 1981.

[8] H. R. Gordon and A. Y. Morel, Remote Assessment of Ocean Color for Interpretation of Satellite Visible Imagery: A Review. New York: Springer-Verlag, 1983. 
[9] H. R. Gordon, O. B. Brown, R. H. Evans, J. W. Brown, R. C. Smith, K. S. Baker, and D. K. Clark, "A semianalytic radiance model of ocean color," J. Geophys. Res., vol. 93, pp. 10909-10924, 1988.

[10] A. Morel, "Optical modeling of the upper ocean in relation to its biogenous matter content (case 1 waters)," J. of Geophys. Res., vol. 93, pp. 10749-10768, 1988.

[11] H. R. Gordon and M. Wang, "Retrieval of water-leaving radiance and aerosol optical thickness over the oceans with SeaWiFS: A preliminary algorithm," Appl. Opt., vol. 33, pp. 443-452, 1994.

[12] M. Wang and H. R. Gordon, "A simple, moderately accurate, atmospheric correction algorithm for SeaWiFS," Rem. Sens. Environ., vol. 50, pp. 231$239,1994$.

[13] H. R. Gordon, "Atmospheric correction of ocean color imagery in the Earth Observing System era," J. Geophys. Res., vol. 102, pp. 17,081-17,106, 1997.

[14] E. P. Shettle and R. W. Fenn, "Models for the Aerosols of the Lower Atmosphere and the Effects of Humidity Variations on Their Optical Properties," U.S. Air Force Geophysics Laboratory, Hanscom Air Force Base, Mass. AFGL-TR-79-0214, 1979.

[15] M. Wang, "A sensitivity study of SeaWiFS atmospheric correction algorithm: Effects of spectral band variations," Remote Sensing of Environment, (accepted) 1998.

[16] H. R. Gordon, "In-orbit calibration strategy for ocean color sensors," Rem. Sens. Environ., vol. 63, pp. 265-278, 1998.

[17] J. E. O'Reilly, S. Maritorena, B. G. Mitchell, D. A. Siegel, K. L. Carder, S. A. Garver, M. Kahru, and C. McClain, "Ocean color chlorophyll algorithms for SeaWiFS," J. of Geophys. Res., in press, 1998. 


\section{Figure Captions}

Figure 1. The errors in retrieved water-leaving reflectance at the MOS spectral bands 443 and $520 \mathrm{~nm}$ compared with the SeaWiFS spectral band configuration using the implemented SeaWiFS atmospheric correction algorithm for aerosol model of Maritime with $\mathrm{RH}=80 \%$ and for various solar zenith angles.

Figure 2. Results from the MOS simple destriping algorithm for a MOS image acquired on February 28, 1998 in the Mediterranean Sea; (a) the MOS original radiance image at $443 \mathrm{~nm}$ and (b) after applying the destriping algorithm.

Figure 3. The TOA radiance at $443 \mathrm{~nm}$ measured by MOS and SeaWiFS for case of January 29, 1998 in the Atlantic ocean.

Figure 4. The derived gain coefficients for the MOS bands from scenes acquired on January 29 and February 28, 1998 for (a)-(g) the MOS bands 1-7 and (h) the retrieved aerosol optical thickness at the MOS band $868 \mathrm{~nm}$.

Figure 5. The histogram (\%) of the MOS retrieved normalized water-leaving reflectances (\%) with and without re-calibrations in comparison with the SeaWiFS measurements for case of January 29, 1998 (Atlantic ocean) for (a)-(d) as for the bands 1-4. For cases of the MOS after re-calibrations, results using both the MOS bands $7 \& 8$ and bands $6 \& 8$ for the atmospheric corrections are presented.

Figure 6. Same as in Figs. 5(a)-5(d) except both MOS and SeaWiFS images were acquired on February 28, 1998 in the Mediterranean Sea.

Figure 7. Same as in Figs. 5(a)-5(d) and 6(a)-6(d) except both MOS and SeaWiFS images were acquired on September 24, 1997 in the Adriatic Sea. For results of 
the MOS after re-calibrations, the MOS bands 6 and 8 were used in the atmospheric corrections.

Figure 8. The histogram (\%) of the MOS retrieved ratio of the normalized waterleaving reflectances between band 2 to 5 and band 3 to 5 in comparison with that of SeaWiFS for cases (a) and (b) January 29, 1998 in the Atlantic ocean; (c) and (d) February 28, 1998 in the Mediterranean sea; and (e) and (f) September 24, 1997 in the Adriatic sea.

Figure 9. The retrieved normalized water-leaving reflectance image (443 nm) from MOS compared with SeaWiFS for a scene acquired on (a) January 29, 1998 in the Atlantic ocean; (b) February 28, 1998 in the Mediterranean sea; and (c) September 24, 1997 in the Adriatic sea. The MOS bands 6 and 8 were used in the atmospheric corrections. 
TABLE 1. MOS and SeaWiFS band center wavelengths.

\begin{tabular}{cccc}
\hline \hline Band \# & $\begin{array}{c}\text { MOS } \\
\lambda(\mathrm{nm})\end{array}$ & $\begin{array}{c}\text { SeaWiFS } \\
\lambda(\mathrm{nm})\end{array}$ & $\begin{array}{c}\text { Difference } \\
\Delta \lambda(\mathrm{nm})\end{array}$ \\
\hline 1 & 408 & 412 & -4 \\
2 & 443 & 443 & 0 \\
3 & 485 & 490 & -5 \\
4 & 520 & 510 & 10 \\
5 & 570 & 555 & 15 \\
6 & 685 & 670 & 15 \\
7 & 750 & 765 & -15 \\
8 & 868 & 865 & 3 \\
\hline
\end{tabular}

TABLE 2(a). MOS retrieved parameters compared with SeaWiFS for a colocated MOS $10 \times 10$ pixels for case of January 29,1998 . The $\left[\rho_{w}\right]_{N}$ is in $\%$.

\begin{tabular}{cccc}
\hline \hline Parameters & MOS & SeaWiFS & Difference (\%) \\
\hline$\left[\rho_{w}(1)\right]_{N}$ & 4.453 & 2.634 & 69.1 \\
{$\left[\rho_{w}(2)\right]_{N}$} & 4.860 & 2.224 & 118.5 \\
{$\left[\rho_{w}(3)\right]_{N}$} & 4.093 & 1.557 & 162.9 \\
{$\left[\rho_{w}(4)\right]_{N}$} & 2.029 & 0.881 & 130.3 \\
\hline$\varepsilon(7,8)$ & 0.198 & 1.015 & - \\
$\tau_{\mathrm{a}}(8)$ & 0.091 & 0.029 & - \\
\hline
\end{tabular}

TABLE 2(b). MOS retrieved parameters compared with SeaWiFS for a colocated MOS $10 \times 10$ pixels for case of February 28,1998 . The $\left[\rho_{w}\right]_{N}$ is in $\%$.

\begin{tabular}{cccc}
\hline \hline Parameters & MOS & SeaWiFS & Difference (\%) \\
\hline$\left[\rho_{w}(1)\right]_{N}$ & 3.325 & 0.903 & 268.2 \\
{$\left[\rho_{w}(2)\right]_{N}$} & 3.839 & 0.945 & 306.2 \\
{$\left[\rho_{w}(3)\right]_{N}$} & 3.620 & 1.090 & 232.1 \\
{$\left[\rho_{w}(4)\right]_{N}$} & 2.488 & 0.834 & 198.3 \\
\hline$\varepsilon(7,8)$ & 0.487 & 1.194 & - \\
$\tau_{\mathrm{a}}(8)$ & 0.095 & 0.029 & - \\
\hline
\end{tabular}


TABLE 3. The derived MOS gain coefficients as $G(\lambda, i)=\sum^{3} c_{n}(\lambda) i^{n}$, for $i=1-384$.

\begin{tabular}{ccccc}
\hline \hline $\begin{array}{c}\text { MOS } \\
\lambda(\mathrm{nm})\end{array}$ & $\mathrm{C}_{0}(\lambda)$ & $\mathrm{C}_{1}(\lambda)$ & $\mathrm{C}_{2}(\lambda)$ & $\mathrm{C}_{3}(\lambda)$ \\
\hline 408 & 0.9029 & $3.5 \times 10^{-4}$ & $-9.0 \times 10^{-7}$ & $1.4 \times 10^{-9}$ \\
443 & 0.8453 & $3.8 \times 10^{-4}$ & $-7.0 \times 10^{-7}$ & $6.5 \times 10^{-10}$ \\
485 & 0.8097 & $3.8 \times 10^{-4}$ & $-5.3 \times 10^{-7}$ & $2.1 \times 10^{-10}$ \\
520 & 0.8693 & $1.7 \times 10^{-4}$ & $-4.9 \times 10^{-8}$ & $2.8 \times 10^{-10}$ \\
570 & 0.8701 & $1.8 \times 10^{-4}$ & $2.2 \times 10^{-7}$ & $-4.6 \times 10^{-10}$ \\
685 & 0.9287 & $7.6 \times 10^{-4}$ & $-2.6 \times 10^{-6}$ & $3.5 \times 10^{-9}$ \\
$750^{\dagger}$ & 1.3208 & $-3.5 \times 10^{-4}$ & $-2.9 \times 10^{-6}$ & $7.4 \times 10^{-9}$ \\
$750 \ddagger$ & 1.2287 & $5.1 \times 10^{-4}$ & $-5.3 \times 10^{-6}$ & $-3.2 \times 10^{-10}$ \\
868 & 1.0000 & 0.0 & 0.0 & 0.0 \\
\hline
\end{tabular}

† From case of Jan. 29, 1998. $\quad$ † From case of Feb. 28, 1998.

TABLE 4. Total number of retrievals contributed in Figs. 5 and 6 for three different cases.

\begin{tabular}{cccc}
\hline \hline Case & \multicolumn{3}{c}{ Total \# of Retrievals } \\
& SeaWiFS & MOS (7 \& 8) & MOS (6 \& 8) \\
\hline Jan. 29, 1998 & $2.27 \times 10^{4}$ & $1.37 \times 10^{5}$ & $1.40 \times 10^{5}$ \\
Feb. 28, 1998 & $2.24 \times 10^{4}$ & $1.38 \times 10^{5}$ & $1.41 \times 10^{5}$ \\
\hline
\end{tabular}


TABLE 5(a). The MOS retrieved parameters compared with SeaWiFS after MOS band re-calibrations for the case of January 29,1998 . The $\left[\rho_{w}\right]_{N}$ is in $\%$.

\begin{tabular}{cccccc}
\hline \hline $\begin{array}{c}\text { Parameter } \\
\text { (Peak value) }\end{array}$ & $\begin{array}{c}\text { SeaWiFS } \\
(7,8)\end{array}$ & $\begin{array}{c}\text { MOS } \\
(7,8)\end{array}$ & $\begin{array}{c}\text { Diff }(\%) \\
(7,8)\end{array}$ & $\begin{array}{c}\text { MOS } \\
(6,8)\end{array}$ & $\begin{array}{c}\text { Diff }(\%) \\
(6,8)\end{array}$ \\
\hline$\left[\rho_{w}(1)\right]_{N}$ & 2.51 & 2.41 & -4.0 & 2.26 & -10.0 \\
{$\left[\rho_{w}(2)\right]_{N}$} & 2.11 & 2.16 & 2.4 & 1.96 & -7.1 \\
{$\left[\rho_{w}(3)\right]_{N}$} & 1.51 & 1.66 & 9.9 & 1.51 & 0.0 \\
{$\left[\rho_{w}(4)\right]_{N}$} & 0.86 & 0.91 & 5.8 & 0.71 & -7.0 \\
\hline$\varepsilon(7,8)$ & 0.983 & 1.009 & - & - & - \\
\hline
\end{tabular}

TABLE 5(b). The MOS retrieved parameters compared with SeaWiFS after MOS band re-calibrations for the case of February 28, 1998. The $\left[\rho_{w}\right]_{N}$ is in $\%$.

\begin{tabular}{cccccc}
\hline \hline $\begin{array}{c}\text { Parameter } \\
(\text { Peak value })\end{array}$ & $\begin{array}{c}\text { SeaWiFS } \\
(7,8)\end{array}$ & $\begin{array}{c}\text { MOS } \\
(7,8)\end{array}$ & $\begin{array}{c}\text { Diff }(\%) \\
(7,8)\end{array}$ & $\begin{array}{c}\text { MOS } \\
(6,8)\end{array}$ & $\begin{array}{c}\text { Diff }(\%) \\
(6,8)\end{array}$ \\
\hline$\left[\rho_{w}(1)\right]_{N}$ & 0.76 & 0.81 & 6.6 & 0.91 & 19.7 \\
{$\left[\rho_{w}(2)\right]_{N}$} & 0.86 & 0.86 & 0.0 & 0.91 & 5.8 \\
{$\left[\rho_{w}(3)\right]_{N}$} & 1.06 & 0.91 & -14.2 & 1.01 & -4.7 \\
{$\left[\rho_{w}(4)\right]_{N}$} & 0.76 & 0.76 & 0.0 & 0.86 & 13.2 \\
\hline$\varepsilon(7,8)$ & 1.159 & 1.159 & - & - & - \\
\hline
\end{tabular}




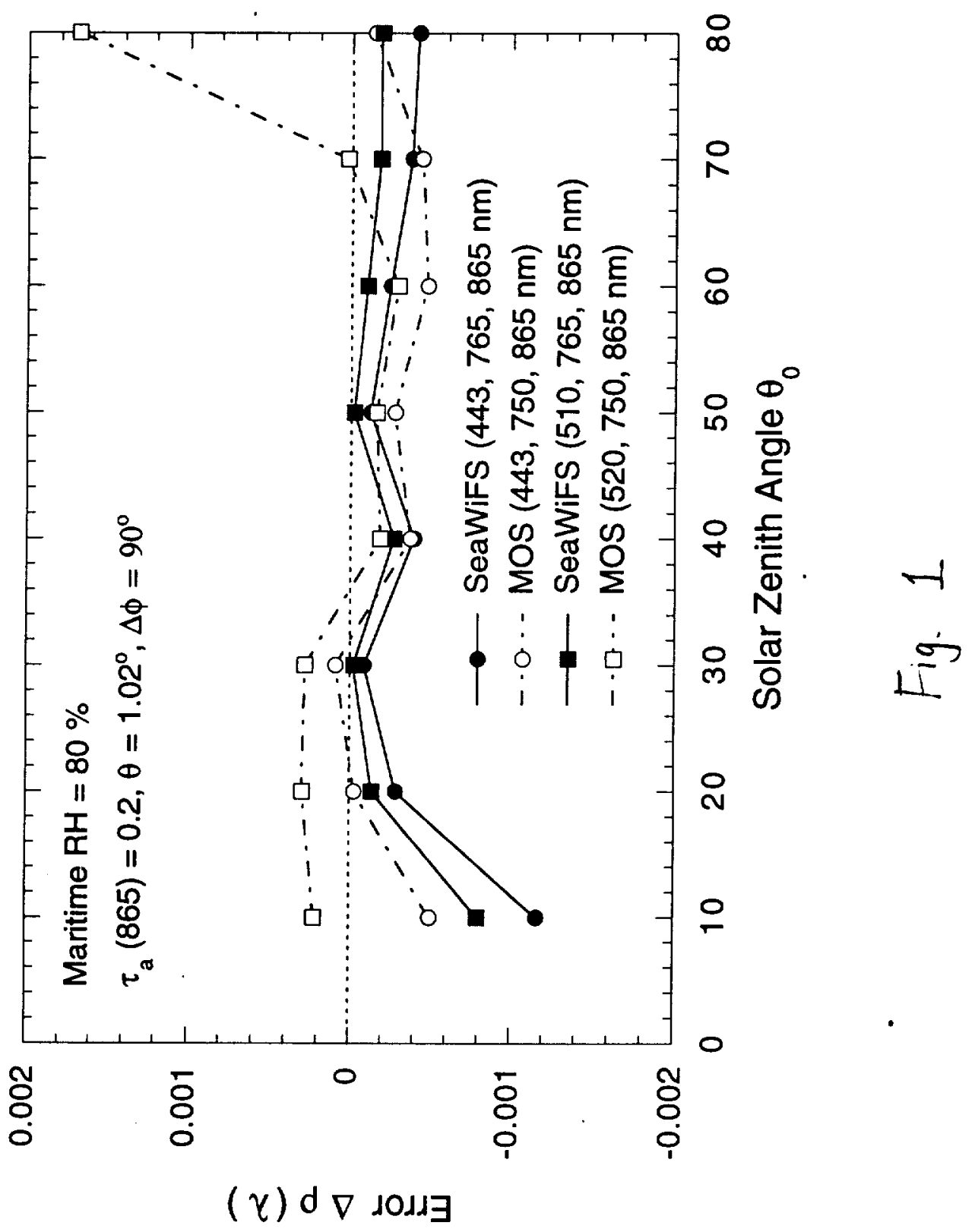



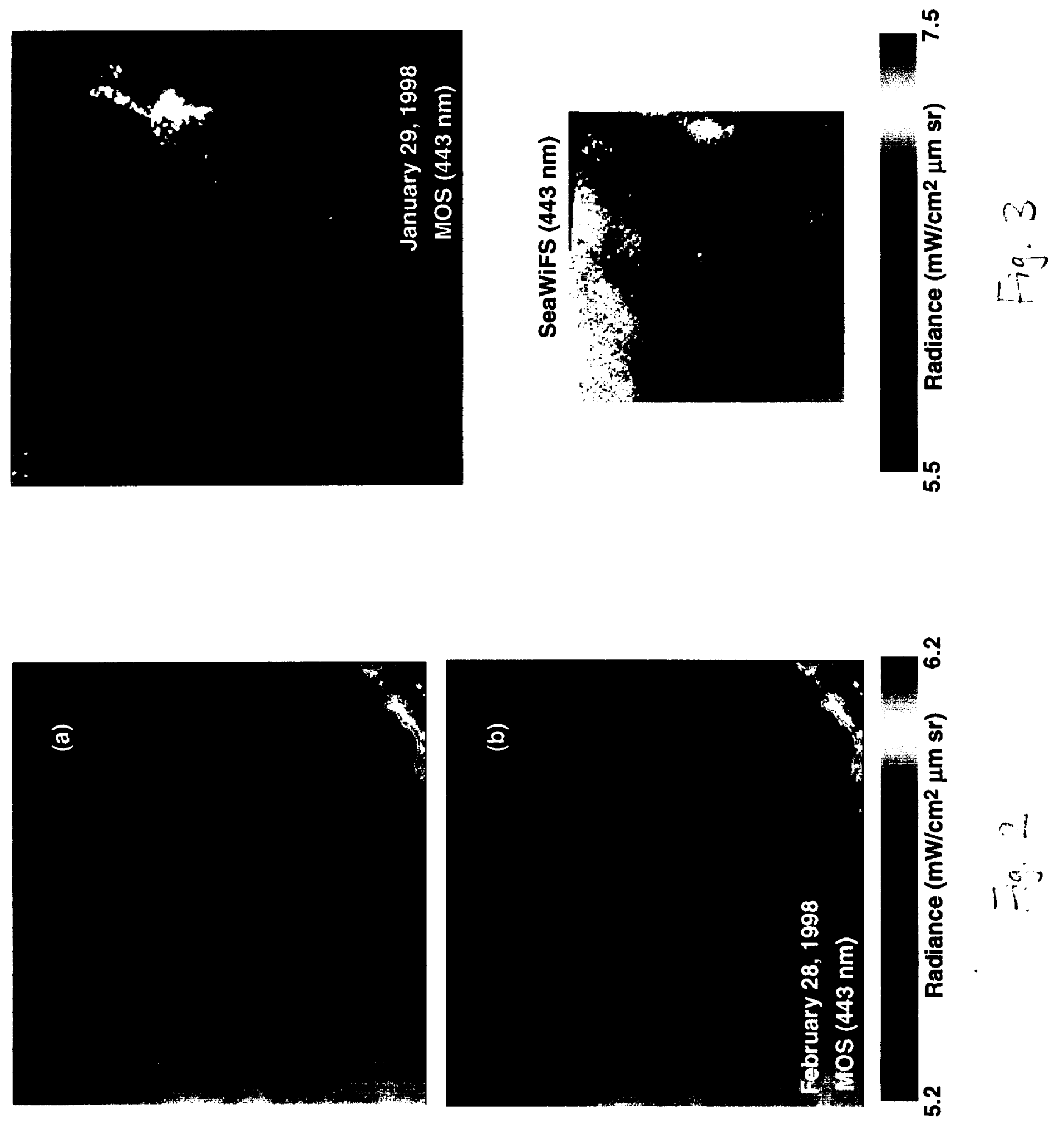

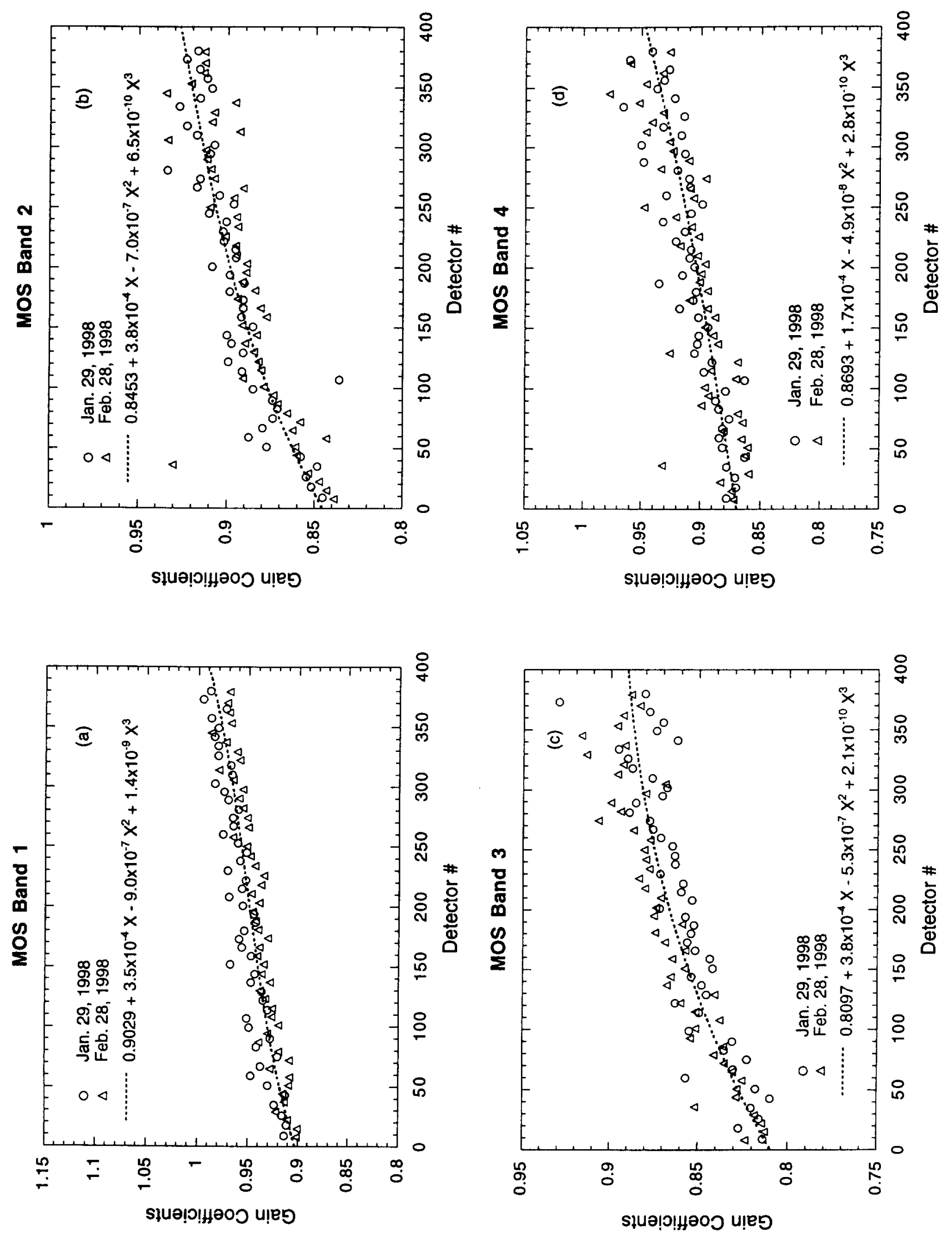

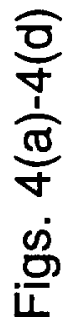




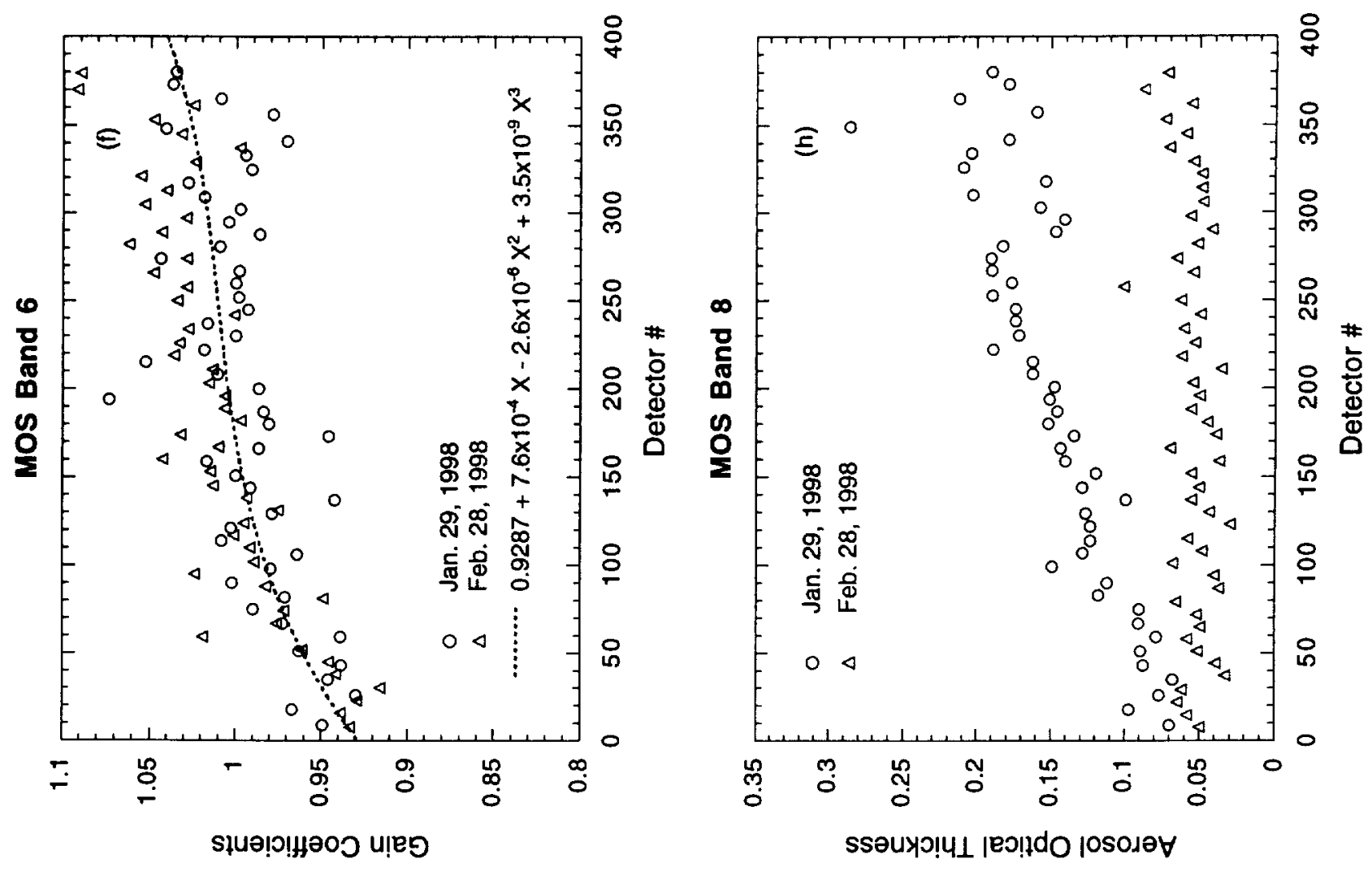

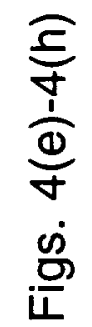
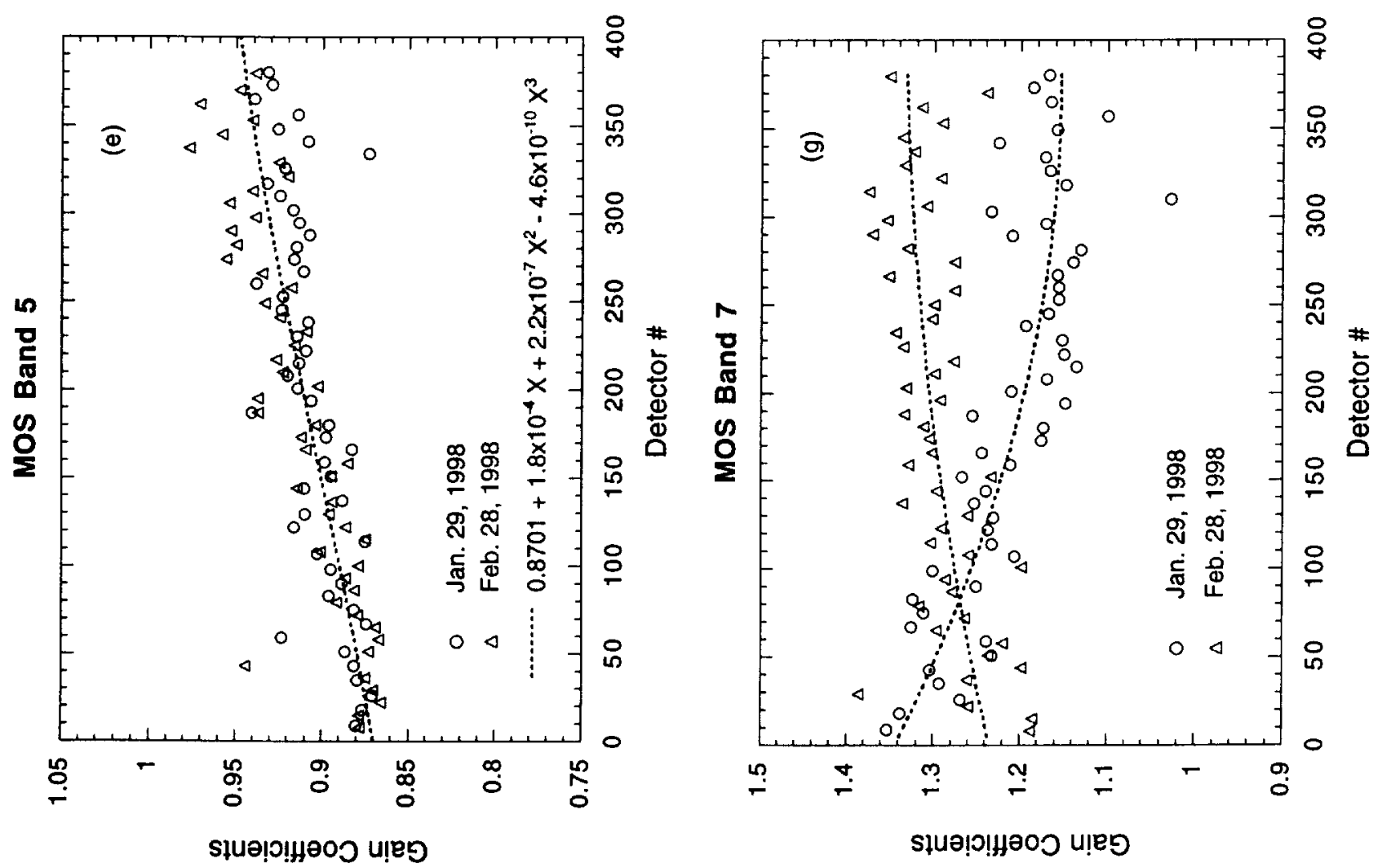

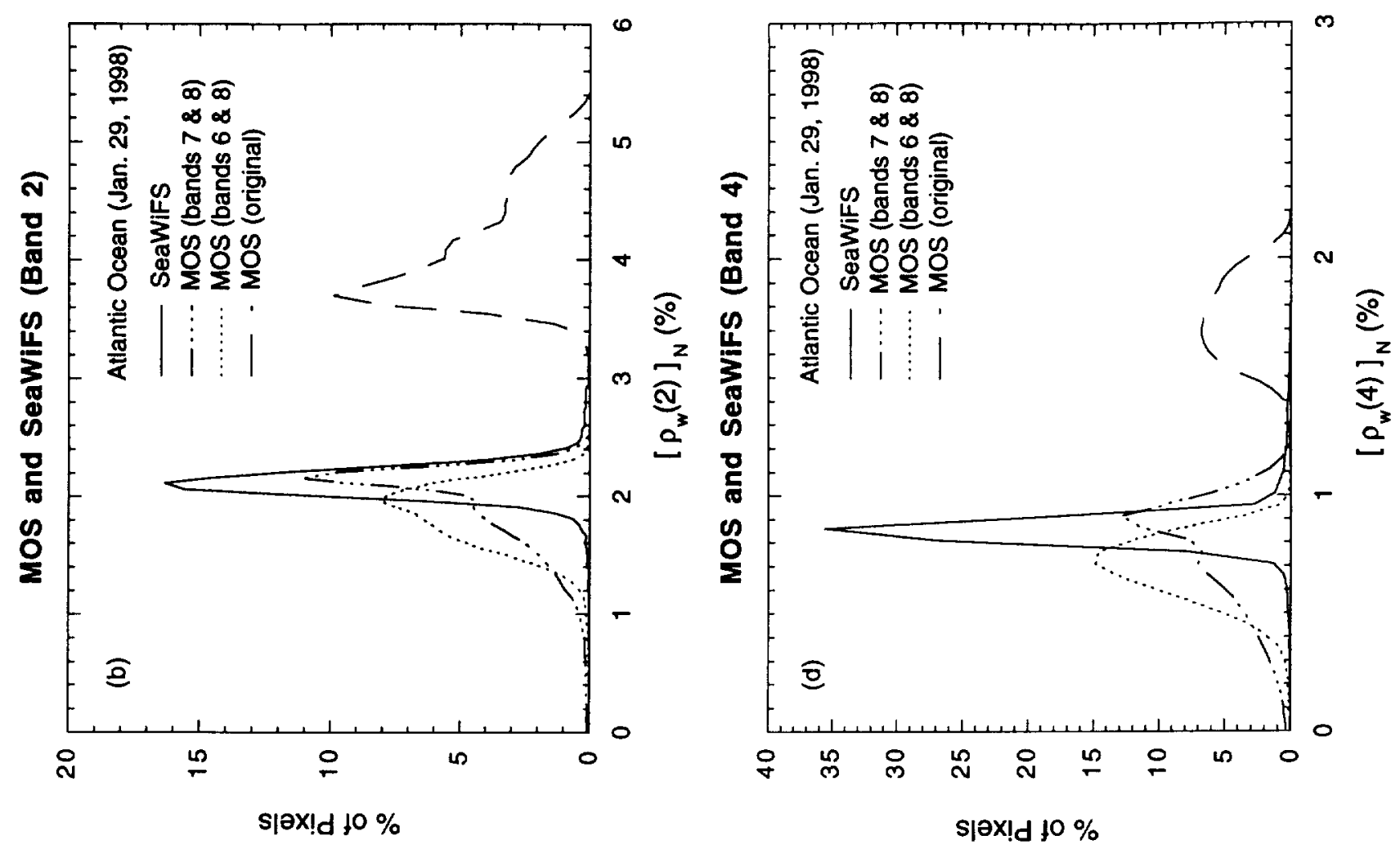

눈
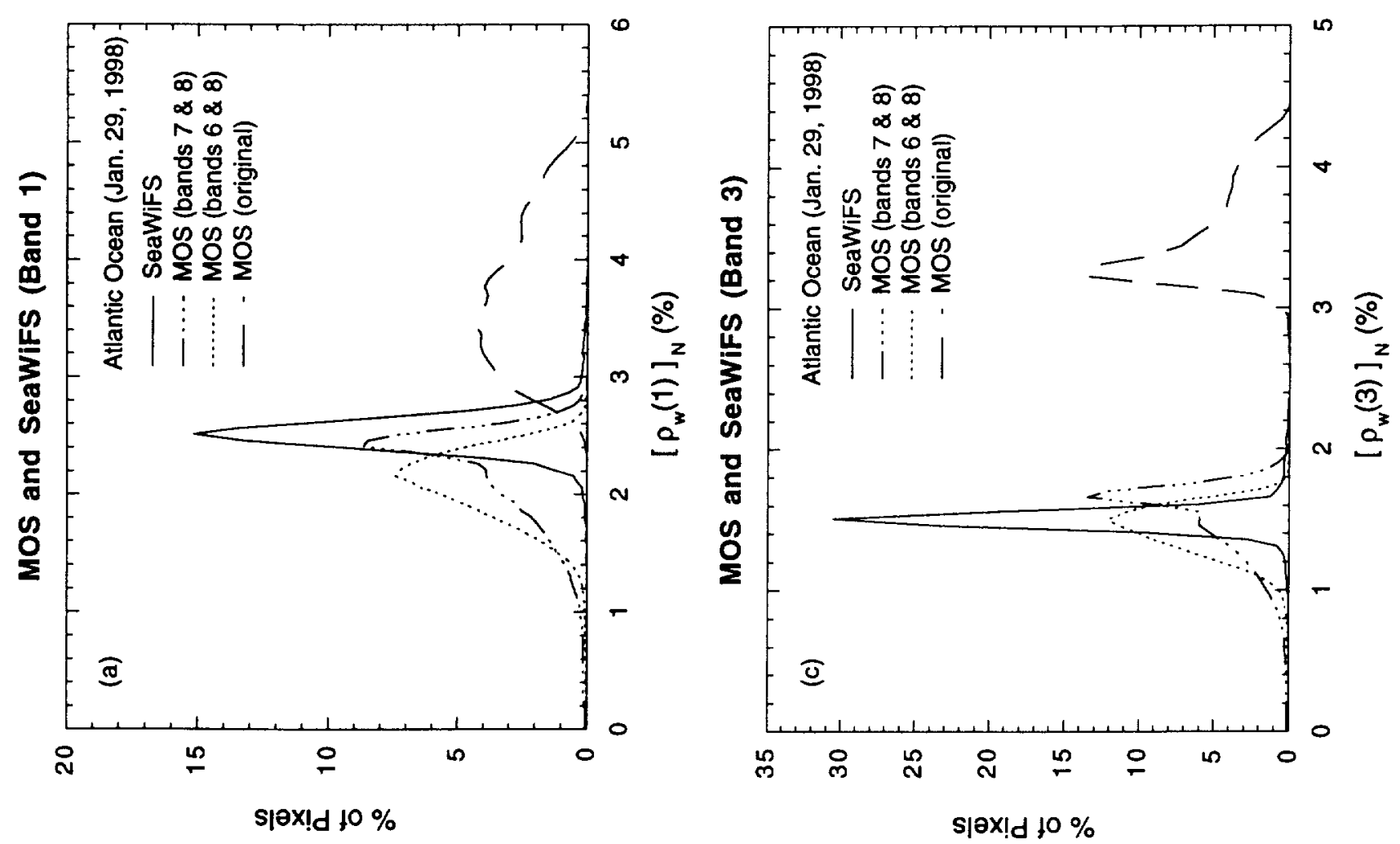

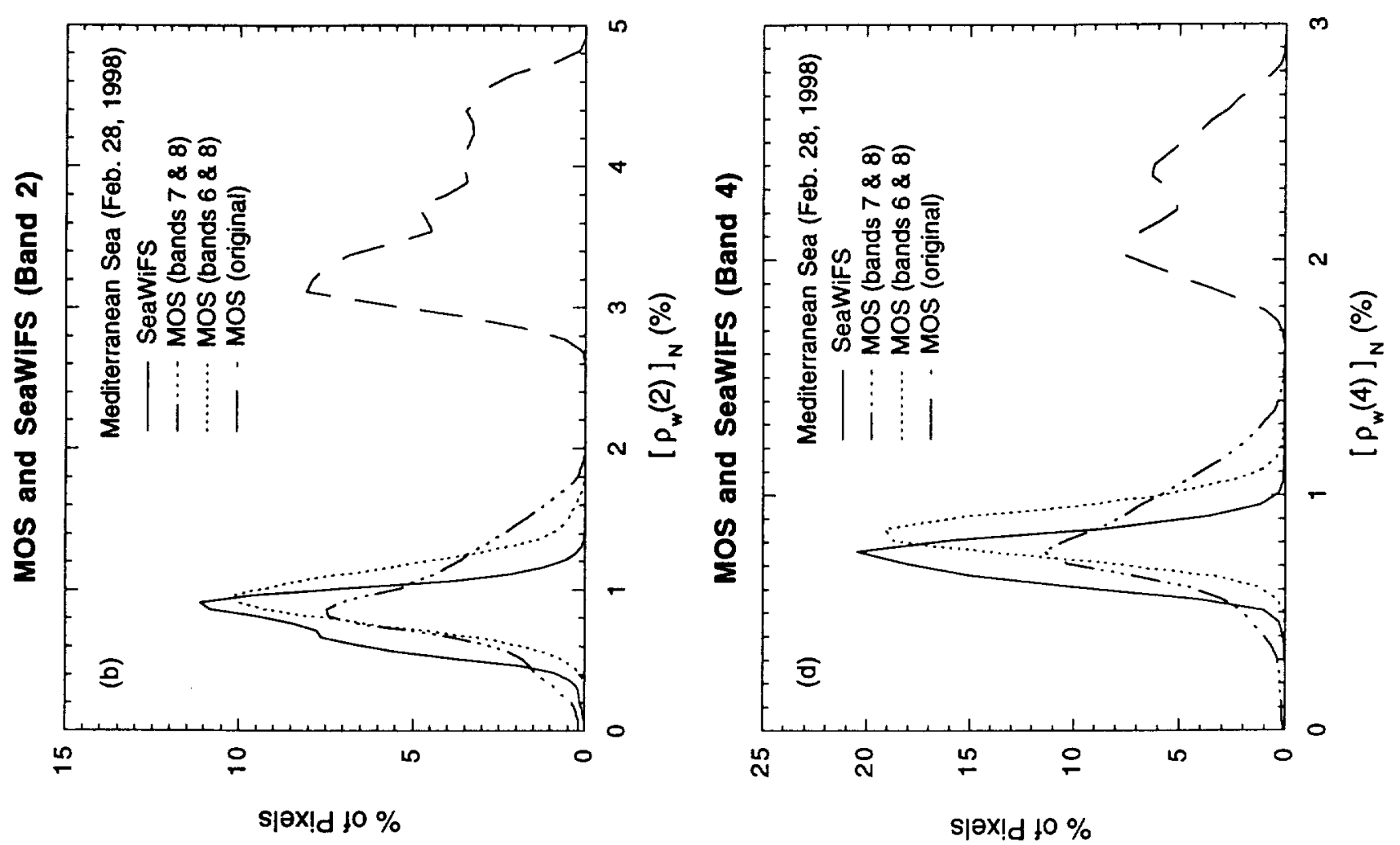

0
$\frac{1}{2}$
$\frac{0}{4}$
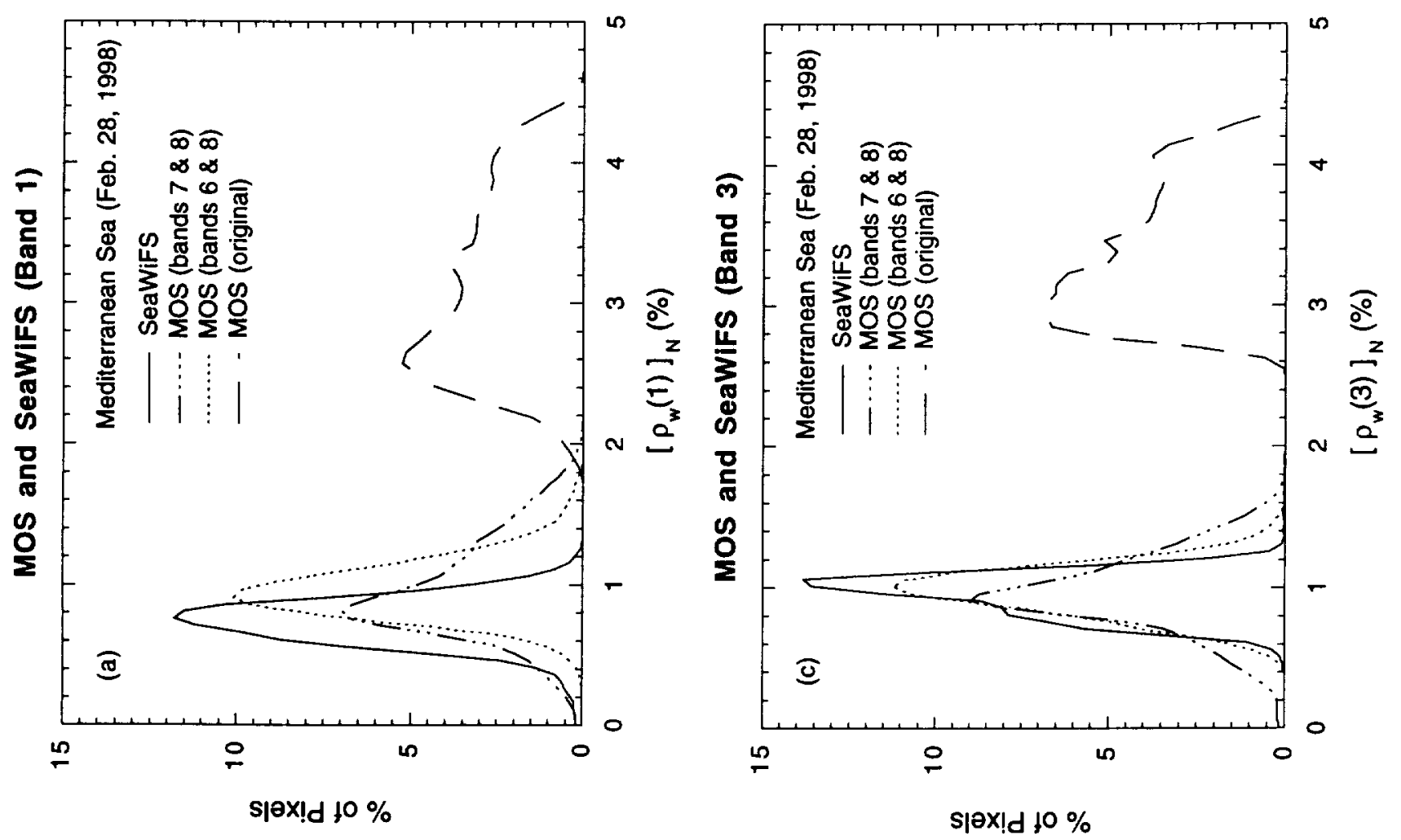

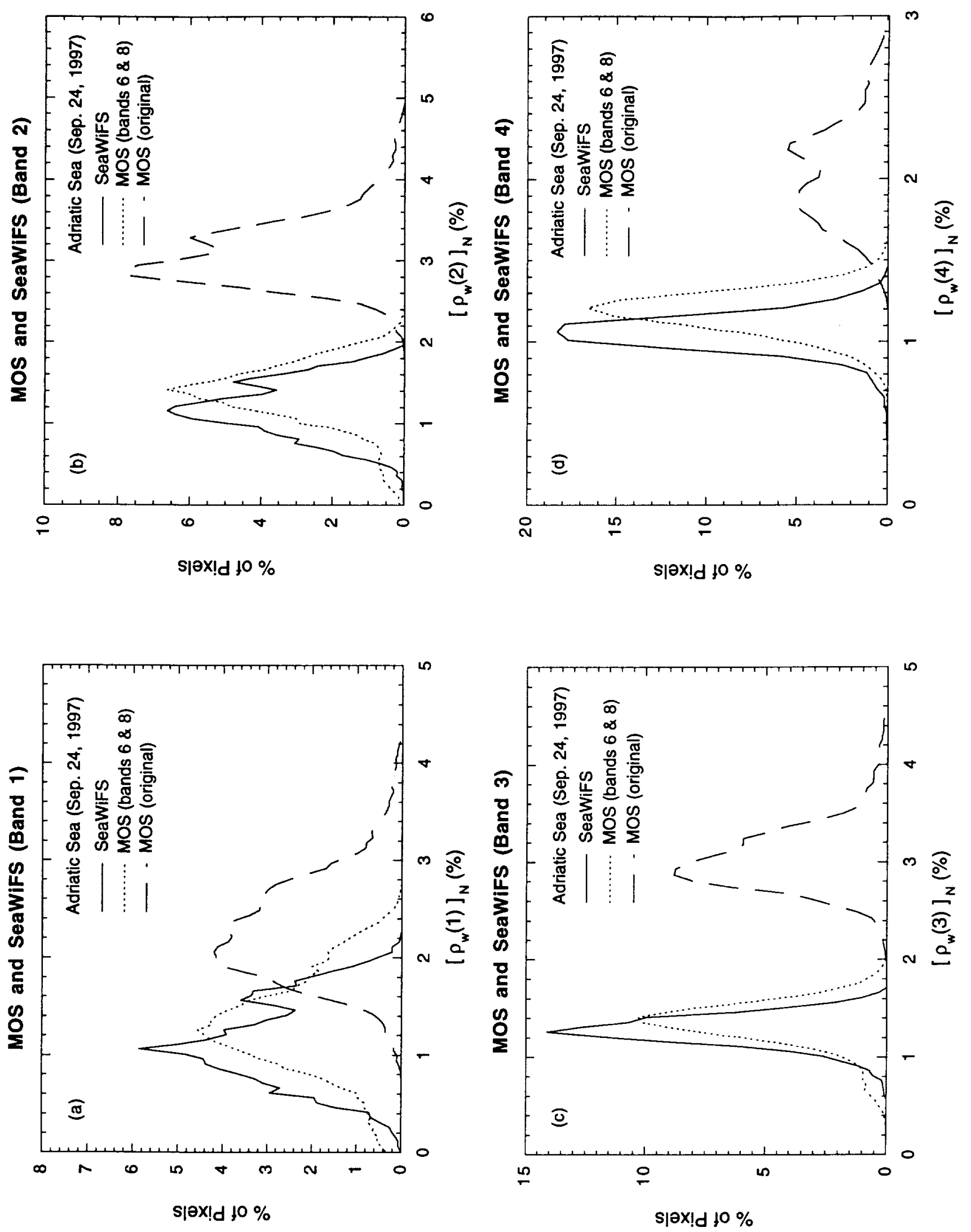

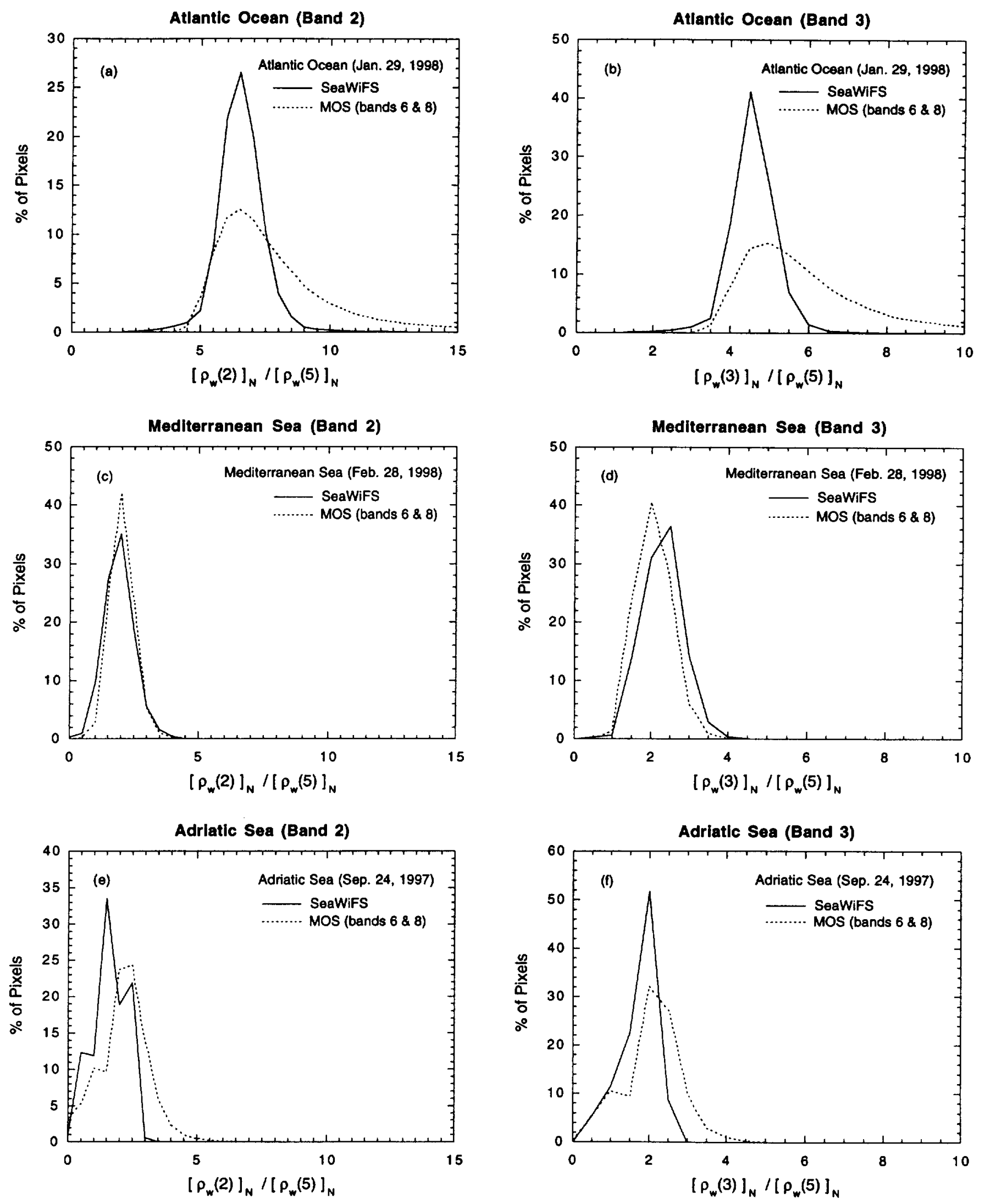

Figure 8. 


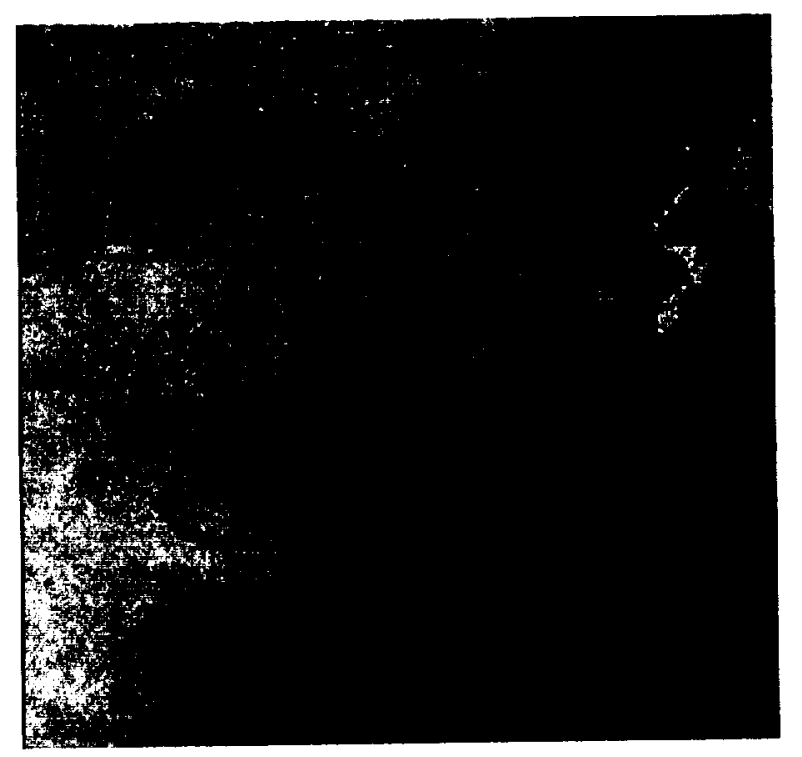

(a)

Atlantic Ocean (Jan. 29, 1998)
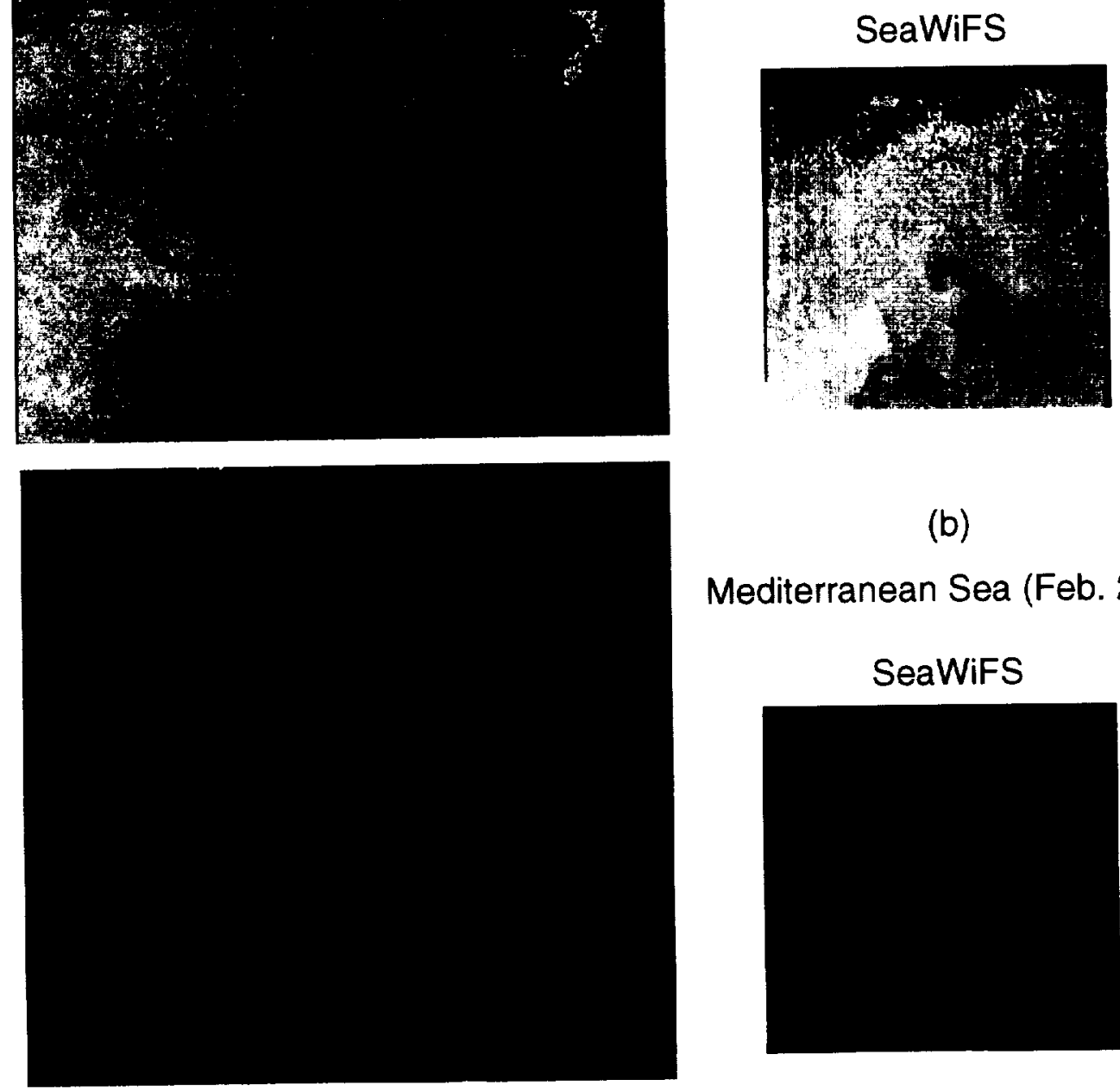

(b)

Mediterranean Sea (Feb. 28, 1998)

SeaWiFS

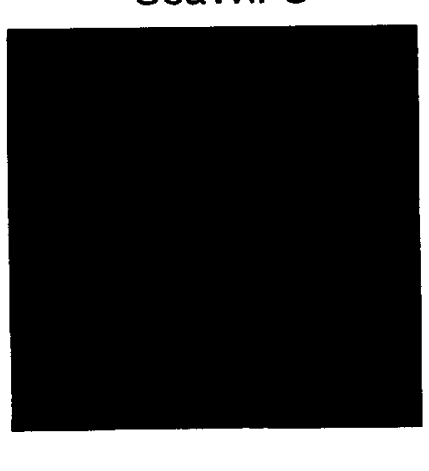

(c)

Adriatic Sea (Sep. 24, 1997)

SeaWiFS

赫

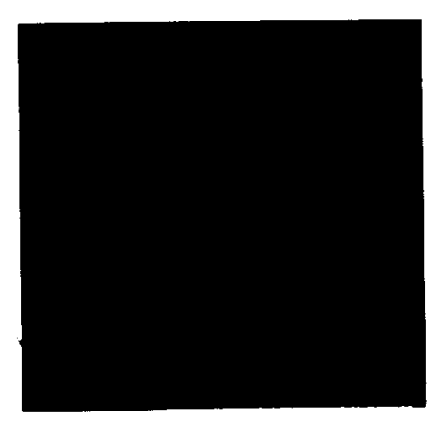

